\title{
Near-Infrared Dyes and Fluorophores Based on Diketopyrrolopyrroles
}

\author{
Georg M. Fischer, Andreas P. Ehlers, Andreas Zumbusch, and Ewald Daltrozzo*
}

\section{Dedicated to Professor Friedrich Dörr on the occasion of his 85th birthday}

Our research activities over the last few decades have concerned correlations between molecular structure and fluorescence. $^{[1,2]}$ A central theme of the research has been the synthesis and spectroscopic investigations of near-infrared (NIR) dyes ${ }^{[3]}$ to get insights into what degree the obtainable fluorescence quantum yields ${ }^{[4,5]}$ are restricted by the $S_{0} \leftrightarrow S_{1}$ energy gap. $^{[6,7]}$ Our results ${ }^{[8]}$ on the condensation of 1,4phthalazinediones with heteroarylacetonitriles in $\mathrm{POCl}_{3}$ prompted us to carry out the reaction with diketopyrrolopyrroles (DPPs) 1. ${ }^{[9]}$ Herein we report the results of the investigations.

To date, attempts to activate the carbonyl group of DPPs with $\mathrm{POCl}_{3}$, and to subsequently convert the intermediates with nucleophiles, only led to monosubstitution or to ring opening. ${ }^{[9,10]}$ The reaction of $\mathbf{1}$ and $\mathbf{2}$ in refluxing toluene with an excess of $\mathrm{POCl}_{3}$ according to Scheme 1 afforded disubstituted NIR dyes 3. The progress of the reaction was controlled by recording absorption spectra and stopping the heating as soon as the DPP was used up and/or products absorbing at short wavelengths appeared. Purification was carried out by digesting the product in acetone and subsequent flash chromatography (silica gel/ $\mathrm{CHCl}_{3}$ or $\mathrm{CH}_{2} \mathrm{Cl}_{2}$ ).

The NIR dyes 3a-3h (the structures and spectroscopic data of $\mathbf{3 b}-\mathbf{3 h}$ can be found in the Supporting Information) were synthesized according to this procedure (Scheme 1) from the reaction of $\mathbf{1}^{[11]}$ and $\mathbf{2}$. The course of the reactions was the same in all cases and side-products with strong absorptions below $350 \mathrm{~nm}$ were observed. These side-products are most likely compounds formed by the opening of the DPPs pentalene ring system.

Prerequisite for the reactions is a certain solubility of the DPPs. ${ }^{[12]}$ This is a feature of all of the DPPs used here with the exception of the 4-methoxy derivative 1b. Remarkably, the 4( $N$-methyl- $N$-octyl amino) derivative 1 e has a much better solubility than all the other DPPs used. Only in the case of the reaction of $\mathbf{1 e}$ with $\mathbf{2 a}$ were we able to isolate the 1:1 condensation product ( $13 \%$ yield).

The heteroarylacetonitriles $\mathbf{2 a}$ and $\mathbf{2 b}$ substituted with a tert-butyl group were used to improve the solubility of the condensation products $\mathbf{3}$. In general, satisfying yields were

[*] G. M. Fischer, A. P. Ehlers, Prof. Dr. A. Zumbusch,

Prof. Dr. E. Daltrozzo

Fachbereich Chemie

Universität Konstanz

Universitätstrasse 10, 78464 Konstanz (Germany)

Fax: (+49) 7531-883043

E-mail: ewald.daltrozzo@uni-konstanz.de

$\square$ Supporting information for this article is available on the WWW under http://www.angewandte.org or from the author.
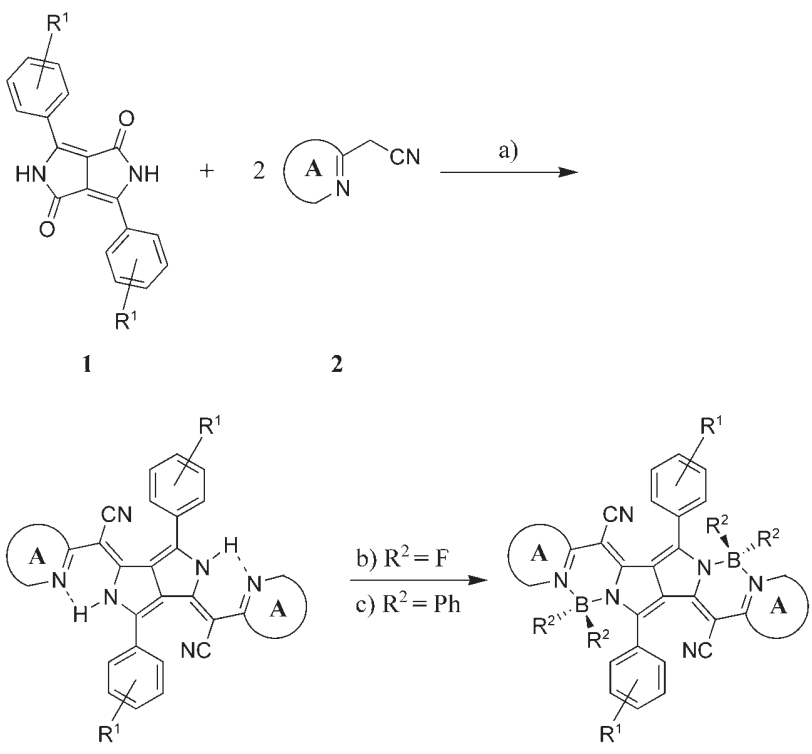

3

4

Scheme 1. Reagents and conditions: a) absolute toluene $/ \mathrm{POCl}_{3}$, reflux; b) 1,2-dichlorobenzene $/ \mathrm{BF}_{3} \cdot \mathrm{Et}_{2} \mathrm{O}$, reflux, diisopropylethylamine; c) xylene/chlorodiphenylborane, reflux; DPPs 1: $R^{1}=4$-octyloxy (1 a), $\mathrm{R}^{1}=4$-methoxy (1 b), $\mathrm{R}^{1}=4$-butyloxy (1 c), $\mathrm{R}^{1}=4$-(hex-5-enyloxy) (1 d), $\mathrm{R}^{1}=4-(N$-methyl- $N$-octylamino) (1 e); heteroarylacetonitriles 2: 2-(6tert-butylquinolin-2-yl)acetonitrile (2a), 2-(6-tert-butylbenzothiazol-2yl)acetonitrile (2b), 2-(quinoxalin-2-yl)acetonitrile (2c), 2-(6-methylpyridin-2-yl)acetonitrile (2d). A: aromatic ring.

obtained only if the solubility of both condensation partners was improved by having longer alkyl groups (Table 1). From these observations we draw the following conclusion concerning the reaction pathway: DPP reacts with $\mathrm{POCl}_{3}$ to form a monophosphorylated intermediate,${ }^{[9]}$ which reacts with the

Table 1: Yield and spectroscopic data of the first electronic transition $\left(\mathrm{S}_{0} \rightarrow \mathrm{S}_{1}\right)$ of $\mathbf{3} \mathbf{a}-\mathbf{3} \mathbf{h}^{\left[{ }^{[a]}\right.}$

\begin{tabular}{|c|c|c|c|c|c|c|}
\hline \multicolumn{2}{|c|}{ Reactants } & \multirow{2}{*}{$\begin{array}{l}\text { NIR } \\
\text { dyes } \\
\mathbf{3 a}\end{array}$} & \multirow{2}{*}{$\begin{array}{l}\text { Yield } \\
{[\%]}\end{array}$} & \multirow{2}{*}{$\begin{array}{l}\lambda_{00} \\
{[\mathrm{~nm}]} \\
731\end{array}$} & \multirow{2}{*}{$\begin{array}{l}\varepsilon_{00} \\
{\left[\mathrm{M}^{-1} \mathrm{~cm}^{-1}\right]}\end{array}$} & \multirow{2}{*}{$\begin{array}{l}f \\
0.71\end{array}$} \\
\hline $1 \mathrm{a}$ & $2 a$ & & & & & \\
\hline $1 \mathrm{a}$ & $2 b$ & $3 b$ & 39 & 735 & 115000 & 0.74 \\
\hline $1 \mathrm{a}$ & $2 c$ & $3 c$ & 7 & 743 & 135000 & 0.72 \\
\hline $1 \mathrm{a}$ & $2 d$ & $3 d$ & 2 & 701 & 70000 & 0.48 \\
\hline $1 \mathrm{~b}$ & $2 a$ & $3 e$ & 4 & 730 & 111000 & 0.68 \\
\hline $1 c$ & $2 a$ & $3 \mathrm{f}$ & 74 & 731 & 103000 & 0.62 \\
\hline $1 d$ & $2 a$ & $3 g$ & 41 & 731 & 115000 & 0.69 \\
\hline $1 \mathrm{e}$ & $2 a$ & $3 \mathrm{~h}$ & 58 & 752 & 115000 & 0.64 \\
\hline
\end{tabular}

[a] In chloroform at room temperature. $\lambda_{00}=$ absorption wavelength, $\varepsilon_{00}=$ molar decadic absorption coefficient, $f=$ oscillator strength. 
heteroarylacetonitrile to give the 1:1 condensation product. Since the solubility of this product is higher than that of the DPP, it reacts faster with an additional equivalent of $\mathrm{POCl}_{3}$ and heteroarylacetonitrile to yield $\mathbf{3}$.

The NIR dyes $\mathbf{3 a}, \mathbf{3 e}, \mathbf{3} \mathbf{f}$, and $\mathbf{3 g}$ differ only in the length of the alkyl groups on the alkoxy substituent. Consequently they show identical absorption spectra at room temperature. The effect of DPP substituents and of the nature of the heteroarylacetonitrile on both the yield and first electronic transition $\left(\lambda_{00}, \varepsilon_{00}\right.$, and oscillatory strength $\left.f\right)$ is summarized in Table 1. Figure 1 shows the first electronic absorption of the dyes obtained from $1 \mathbf{a}$ and $\mathbf{2 a - 2 d}$. Whereas the absorption of

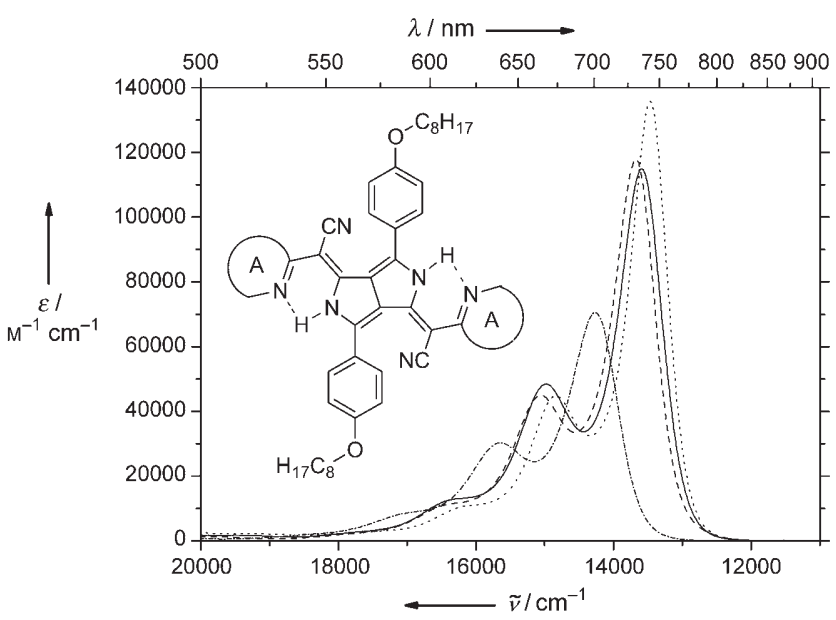

Figure 1. Absorption of the NIR dyes $3 \mathbf{a}(-), 3 \mathbf{b}(---), \mathbf{3} \mathbf{c}(\cdots \cdots)$, and $\mathbf{3} \mathbf{d}(-\cdot-\bullet)$ with the DPP core $\mathbf{1} \mathbf{a}$ in chloroform at room temperature.

the quinoline, benzothiazole, and quinoxaline derivative differ only slightly, the absorption of the pyridine derivate is hypsochromically and hypochromically shifted, which agrees with theoretical predictions.

The large intramolecular mobility (high amplitude torsional vibrations of the heteroaromatic terminal groups) of the NIR dyes 3 in solution results in no fluorescence being observed at room temperature. Substitution of the protons in both $\mathrm{N}-\mathrm{H} \cdots \mathrm{N}$ bridges in 3 by a $\mathrm{BF}_{2}$ or $\mathrm{BPh}_{2}$ group proved to be the most convenient method to rigidize the chromophore and thus eliminate efficient torsions by radiationless $S_{1}$ decay. ${ }^{[2]}$ The desired difluoroboryl chelates 4 were obtained by the reaction of $\mathbf{3}$ with boron trifluoride etherate and Hünig's base in refluxing 1,2-dichlorobenzene-for example, 4a was obtained in $61 \%$ yield from 3a. Compound $4 \mathbf{a}$ is stable in dichloromethane: the absorption does not change upon illumination for several hours at $366 \mathrm{~nm}$. Analogous results were obtained for $\mathbf{3 e}$ and $\mathbf{3 f}$. To our surprise, the difluoroboryl derivate of the benzothiazole dye $\mathbf{3 b}$ could not be isolated because of its lability. Heating $\mathbf{3 a}$ in xylene and addition of chlorobiphenylborane afforded the diphenylboryl chelate $\mathbf{4} \mathbf{a}^{\prime}$ in a yield of $56 \%$. As expected, all chelates 4 show intense NIR fluorescence at room temperature.

Table 2 gives the characterization data of the first electronic transition and the fluorescence for the boron
Table 2: Spectroscopic data of the first electronic transition $\left(S_{0} \leftrightarrow S_{1}\right)$ of the difluoroboryl chelate $4 \mathrm{a}$ and diphenylboryl chelate $4 \mathrm{a}^{\prime}{ }^{[\mathrm{a}]}$

\begin{tabular}{lllllll}
\hline 4 & $\begin{array}{l}\lambda_{00}^{A} \\
{[\mathrm{~nm}]}\end{array}$ & $\begin{array}{l}\lambda_{00}^{F} \\
{[\mathrm{~nm}]}\end{array}$ & $\begin{array}{l}\Delta \tilde{v}_{A-F} \\
{\left[\mathrm{~cm}^{-1}\right]}\end{array}$ & $\begin{array}{l}\varepsilon_{00} \\
{\left[\mathrm{M}^{-1} \mathrm{~cm}^{-1}\right]}\end{array}$ & $f$ & $\Phi_{F}$ \\
\hline $4 \mathrm{a}$ & 754 & 773 & 320 & 205000 & 0.83 & 0.59 \\
$\mathbf{4 \mathbf { a } ^ { \prime }}$ & 819 & 831 & 180 & 256000 & 0.76 & 0.53 \\
\hline
\end{tabular}

[a] In chloroform at room temperature. $\lambda_{00}^{A} / \lambda_{00}^{F}=$ absorption/emission wavelength, $\Delta \tilde{\nu}_{A-F}=$ Stokes shift, $\varepsilon_{00}=$ molar decadic absorption coefficient, $f=$ oscillator strength, $\Phi_{F}=$ fluorescence quantum yield.

chelates $4 \mathbf{a}$ and $4 \mathbf{a}^{\prime}$. A comparison of the long-wavelength absorptions of $\mathbf{3 a}, \mathbf{4 a}$, and $\mathbf{4} \mathbf{a}^{\prime}$ (Figure 2) clearly demonstrates the effects of chromophore stiffening: a) sharpening of the vibronic bands $\left(\Delta \tilde{v}_{1 / 2} \approx 750 \mathrm{~cm}^{-1}\right.$ for $\mathbf{3 a}$ versus $\Delta \tilde{v}_{1 / 2}$ $\approx 500 \mathrm{~cm}^{-1}$ for $4 \mathbf{a}$ and $\Delta \tilde{\nu}_{1 / 2} \approx 400 \mathrm{~cm}^{-1}$ for $4 \mathbf{a}^{\prime}$ ), b) increase in the $\varepsilon_{00}$ and $f\left(S_{0} \rightarrow S_{1}\right)$ values, c) shift of the Franck-Condon factors in favor of the 00 transition.

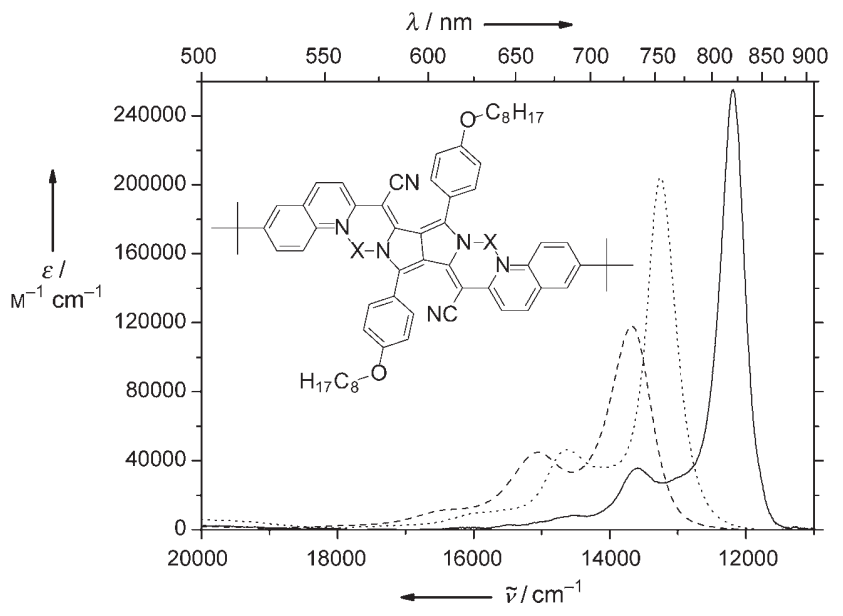

Figure 2. Absorption of $3 \mathrm{a}, \mathrm{X}=\mathrm{H}(-\cdots), \mathbf{4 a}\left(X=B F_{2}, \cdots \cdot \cdot\right)$, and $4 \mathrm{a}^{\prime}$ $\left(\mathrm{X}=\mathrm{BPh}_{2},-\right)$ in chloroform at room temperature.

Compound $4 \mathbf{a}$ has a rigid planar chromophore, whereas $\mathbf{4} \mathbf{a}^{\prime}$ is somewhat twisted as a result of the steric requirements of the phenyl rings of the $\mathrm{BPh}_{2}$ group. This finding explains the lower $\mathrm{S}_{0} \rightarrow \mathrm{S}_{1}$ transition moment $\left(f=0.76\right.$ for $\mathbf{4} \mathbf{a}^{\prime}$ versus $f=$ 0.83 for $4 \mathbf{a})$. The smaller half-width of the 00 band $^{[13]}$ indicates that the asymmetrical torsional potential for $\mathbf{4} \mathbf{a}^{\prime}$ on the side of the small torsional angle is steeper than the symmetrical torsional potential of $\mathbf{4 a}$. The bathochromic shift of $4 \mathbf{a}$ to $4 \mathbf{a}^{\prime}$ is the expected consequence of the different $\sigma$ inductive effects of $\mathrm{BF}_{2}$ and $\mathrm{BPh}_{2}$ on the chromophoric system.

The room-temperature fluorescence quantum yields of 0.59 and 0.53 for $\mathbf{4 a}$ and $\mathbf{4} \mathbf{a}^{\prime}$, respectively (with an error of less than $10 \%)$, in chloroform at emission wavelengths $\left(\lambda_{00}^{F}\right)$ of $773 \mathrm{~nm}$ and $831 \mathrm{~nm}$, respectively, are, to our knowledge, far higher than for any other known fluorophore.

In contrast to the naphthalenediimides ${ }^{[14]}$ and the rylenediimides, ${ }^{[15]}$ there are only small changes in the molecular geometry resulting from the first electronic excitation in our systems, that is, the potential surfaces of $S_{0}$ and $S_{1}$ are very 
similar. Thus, the intensities of the vibrational transitions are strongly shifted towards the 00 transition. This effect combined with the appearance of the 00 band above $800 \mathrm{~nm}$ in the spectrum results in $\mathbf{4 a}^{\prime}$ coming close to being an ideal selective NIR absorber (intense absorption in the nearinfrared range, but extremely low absorptions in the visible range from 700 to $380 \mathrm{~nm}$ ), as is shown by the absorption of $\mathbf{4} \mathbf{a}^{\prime}$ in methylcyclohexane (Figure 3). Selective NIR absorbers are of technical interest for NIR laser welding of transparent polymers. ${ }^{[16]}$

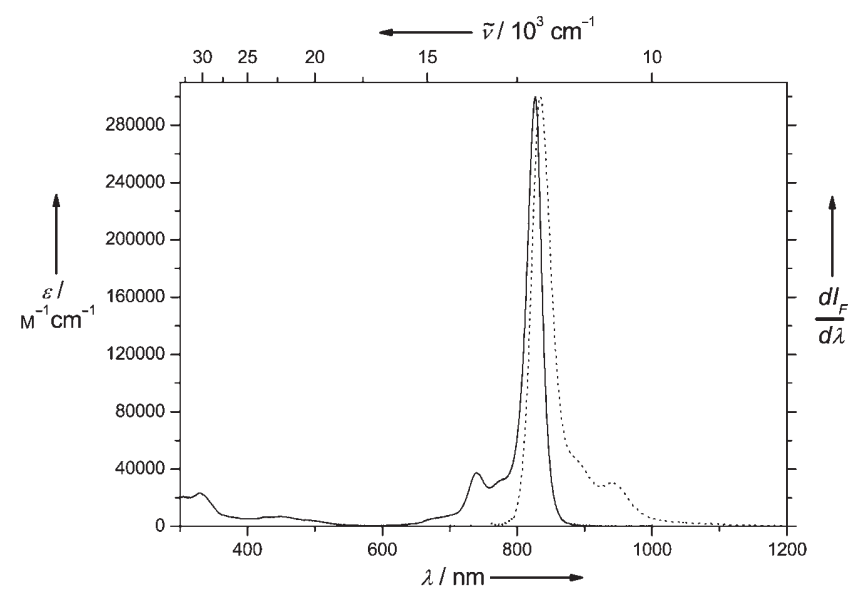

Figure 3. Absorption (-) and fluorescence $(\cdots \cdot \cdot)$ of $4 a^{\prime}$ in methylcyclohexane at room temperature.

In conclusion, the condensation of sufficiently soluble diketopyrrolopyrroles with 2-heteroarylacetonitriles provides a new approach to dyes $\mathbf{3}$ with strong NIR absorptions. Stiffening the chromophore affords NIR fluorophores 4 which results in spectacular properties becoming available. Future applications of the dyes as NIR labels could be accomplished by their functionalization. The first steps towards this goal were already achieved by the synthesis of systems with terminal alkene groups.

\section{Experimental Section}

The fluorescence quantum yields were determined on diluted solutions $\left(c<2 \times 10^{-6} \mathrm{M}\right)$ with a home-made spectrometer. ${ }^{[7]} \mathrm{A}$ $\mathrm{HeNe}$ laser or a $804-\mathrm{nm}$ diode laser were used as the excitation sources, and a germanium diode (NORTHCOAST) used as the detector. CZ 144 (= DY-665-X, Dyomics) was used as a reference dye $\left(\Phi_{F}=0.60\right.$ in $\left.\mathrm{CH}_{2} \mathrm{Cl}_{2}\right)$. $^{[17]}$

General procedure for the synthesis of NIR dyes 3: $\mathrm{POCl}_{3}$ $(8 \mathrm{mmol})$ was added to a mixture of DPP $\mathbf{1}(1 \mathrm{mmol})$ and heteroarylacetonitrile $2(2.5 \mathrm{mmol})$ in absolute toluene $(20 \mathrm{~mL})$ at reflux in a nitrogen atmosphere. The reaction was monitored by UV/Vis/NIR spectroscopy and thin-layer chromatography. As soon as the DPP was used up or short-wavelength-absorbing by-products increased, the reaction was stopped. After removal of the toluene and excess $\mathrm{POCl}_{3}$ by vacuum distillation, the crude product was dissolved in $\mathrm{CH}_{2} \mathrm{Cl}_{2}$ and neutralized with aqueous $\mathrm{NaHCO}_{3}$ solution. The organic phase was separated and dried with $\mathrm{MgSO}_{4}$. After removing the solvent, the residue was dissolved in acetone in an ultrasonic bath. The remaining solid was separated by filtration, washed with acetone, and purified by column chromatography.

3a: Column chromatography (silica gel/ $\mathrm{CHCl}_{3}$ ) afforded $\mathbf{3 a}$ as a green crystalline powder in $33 \%$ yield. ${ }^{1} \mathrm{H} \mathrm{NMR}\left(400 \mathrm{MHz}, \mathrm{CDCl}_{3}\right.$ ): $\delta=14.78$ (brs, $2 \mathrm{H} ; \mathrm{N}-\mathrm{H}), 7.96\left(\mathrm{~d},{ }^{3} \mathrm{~J}=8.8 \mathrm{~Hz}, 2 \mathrm{H} ; \mathrm{H}-4^{\prime}\right), 7.77$ (m, 8H; $\left.\mathrm{AA}^{\prime}, \mathrm{H}-7^{\prime}, \mathrm{H}-8^{\prime}\right), 7.65$ (d, $\left.{ }^{3} \mathrm{~J}=8.8 \mathrm{~Hz}, 2 \mathrm{H} ; \mathrm{H}-3^{\prime}\right), 7.63$ (s, 2H; H-5'), $7.14\left(\mathrm{~m}, 4 \mathrm{H} ; \mathrm{XX}^{\prime}\right), 4.10\left(\mathrm{t},{ }^{3} J=6.6 \mathrm{~Hz}, 4 \mathrm{H} ; \mathrm{OCH}_{2}\right), 1.86(\mathrm{~m}, 4 \mathrm{H}$; $\left.\mathrm{OCH}_{2} \mathrm{CH}_{2}\right), 1.6-1.3\left(\mathrm{~m}, 38 \mathrm{H}\right.$; alkyl, tert-butyl), $0.92 \mathrm{ppm}\left(\mathrm{t},{ }^{3} \mathrm{~J}=\right.$ 6,8 Hz, 6H; $\left.\mathrm{CH}_{3}\right)$. MALDI-MS: $\mathrm{m} / z$ calcd: $957.6[M+\mathrm{H}]^{+}, 979.6$ $[M+\mathrm{Na}]^{+}, 995.5[M+\mathrm{K}]^{+}$; found: $956.8,978.8,995.7 ; \mathrm{UV} / \mathrm{Vis} / \mathrm{NIR}$ $\left(\mathrm{CHCl}_{3}\right): v_{00}=13700 \mathrm{~cm}^{-1}\left(\lambda_{00}=731 \mathrm{~nm}\right) ; \varepsilon_{00}=118000 \mathrm{M}^{-1} \mathrm{~cm}^{-1}, f=$ 0.71. Elemental analysis calcd (\%) for $\mathrm{C}_{64} \mathrm{H}_{72} \mathrm{~N}_{6} \mathrm{O}_{2} \quad[M=$ 957.30 $\mathrm{g} \mathrm{mol}^{-1}$ ]: C 80.30, H 7.58, N 8.78; found: C 80.36, H 7.67, N 8.37 .

4a: $\mathrm{BF}_{3} \cdot \mathrm{Et}_{2} \mathrm{O}(0.98 \mathrm{~mL}, 1.77 \mathrm{~g}, 7.38 \mathrm{mmol})$ was added to a solution of $\mathbf{3 a}(500 \mathrm{mg}, 0.52 \mathrm{mmol})$ in ortho-dichlorobenzene $(15 \mathrm{~mL})$ at reflux in a nitrogen atmosphere. After $10 \mathrm{~min}$, Hünig's base $(0.22 \mathrm{~mL}, 169 \mathrm{mg}, 1.31 \mathrm{mmol})$ was added and the mixture heated at reflux for a further $10 \mathrm{~min}$. The reaction was then stopped. After removal of the solvent and excess $\mathrm{BF}_{3} \cdot \mathrm{Et}_{2} \mathrm{O}$, the crude product was dissolved in methanol in an ultrasonic bath and separated by filtration. Column chromatography (silica gel/ $\mathrm{CH}_{2} \mathrm{Cl}_{2}$ ) afforded $\mathbf{4 a}$ in $76 \%$ yield $(420 \mathrm{mg}, 0.40 \mathrm{mmol})$ as a green powder. ${ }^{1} \mathrm{H} \mathrm{NMR}$ $\left(400 \mathrm{MHz}, \mathrm{C}_{2} \mathrm{D}_{2} \mathrm{Cl}_{4}\right): \delta=8.42\left(\mathrm{~m}, 2 \mathrm{H} ; \mathrm{H}-8^{\prime}\right), 8.14\left(\mathrm{~d},{ }^{3} J=9.3 \mathrm{~Hz}, 2 \mathrm{H}\right.$; H-4'), $7.74\left(\mathrm{dd},{ }^{3} J=9.5 \mathrm{~Hz},{ }^{4} J=2.2 \mathrm{~Hz}, 2 \mathrm{H} ; \mathrm{H}-7^{\prime}\right), 7.72$ (d, 4 H; AA'), 7.66 (m, 4H; H-3',H-5'), 7.06 (m, 4H; XX'), 4.08 (t, ${ }^{3} J=6.6 \mathrm{~Hz}, 4 \mathrm{H}$; $\left.\mathrm{OCH}_{2}\right), 1.85\left(\mathrm{~m}, 4 \mathrm{H} ; \mathrm{OCH}_{2} \mathrm{CH}_{2}\right), 1.53\left(\mathrm{~m}, 4 \mathrm{H} ; \mathrm{O}\left(\mathrm{CH}_{2}\right)_{2} \mathrm{CH}_{2}\right), 1.45-$ 1.2 (brs, $16 \mathrm{H}$; alkyl), 1.36 (s, $18 \mathrm{H}$; tert-butyl), $0.91 \mathrm{ppm}\left(\mathrm{t}, 6 \mathrm{H} ; \mathrm{CH}_{3}\right)$. MALDI-MS: $m / z$ calcd: $1053.6[M+\mathrm{H}]^{+}, 1075.6[M+\mathrm{Na}]^{+}$; found: 1053.1, 1076.1; UV/Vis/NIR $\quad\left(\mathrm{CHCl}_{3}\right): \quad v_{00}^{A}=13260 \mathrm{~cm}^{-1} \quad\left(\lambda_{00}^{A}=\right.$ $754 \mathrm{~nm}), \quad \varepsilon_{00}=205000 \mathrm{M}^{-1} \mathrm{~cm}^{-1}, \quad f=0.83 ; \quad v_{00}^{F}=12940 \mathrm{~cm}^{-1} \quad\left(\lambda_{00}^{F}=\right.$ $773 \mathrm{~nm}), \quad \Phi_{F}=0.59$. Elemental analysis calcd (\%) for $\mathrm{C}_{64} \mathrm{H}_{70} \mathrm{~B}_{2} \mathrm{~F}_{4} \mathrm{~N}_{6} \mathrm{O}_{2}\left[M=1052.90 \mathrm{~g} \mathrm{~mol}^{-1}\right]:$ C 73.01, H 6.70, N 7.98; found: $\mathrm{C} 72.51, \mathrm{H} 6.95, \mathrm{~N} 7.83$.

$4 \mathbf{a}^{\prime}$ : A mixture of $\mathbf{3 a}(250 \mathrm{mg}, 0.26 \mathrm{mmol})$ and $(321 \mathrm{mg}, 1.6 \mathrm{mmol})$ chlorodiphenylborane was refluxed in absolute xylene $(15 \mathrm{~mL})$ under nitrogen. After $10 \mathrm{~min}$ at reflux, the reaction was stopped, xylene removed, and the residue purified by column chromatography (silica gel $\left./ \mathrm{CH}_{2} \mathrm{Cl}_{2}\right)$ to afford $\mathbf{4 a}^{\prime}$ as a yellow solid in $56 \%$ yield $(189 \mathrm{mg}$, $0.147 \mathrm{mmol}$ ). ${ }^{1} \mathrm{H} \mathrm{NMR}\left(400 \mathrm{MHz}, \mathrm{C}_{2} \mathrm{D}_{2} \mathrm{Cl}_{4}\right): \delta=8.18\left(\mathrm{~d},{ }^{3} J=9.5 \mathrm{~Hz}\right.$, $2 \mathrm{H} ; \mathrm{H}-8^{\prime}$ ), 7.83 (d, $\left.{ }^{3} J=9.3 \mathrm{~Hz}, 2 \mathrm{H} ; \mathrm{H}-4^{\prime}\right), 7.58$ (d, ${ }^{3} J=9.3 \mathrm{~Hz}, 2 \mathrm{H} ; \mathrm{H}-$ $\left.3^{\prime}\right), 7.34$ (m, 10H; H-5', $m$-phenyl), $7.15\left(\mathrm{dd},{ }^{3} \mathrm{~J}=9.5 \mathrm{~Hz},{ }^{4} \mathrm{~J}=2.2 \mathrm{~Hz}\right.$, $2 \mathrm{H}$; H-7') 7.10 (m, 12 H; o- ,p-phenyl), 6.52 (d, 4H; AA'), 6.06 (m, $\left.4 \mathrm{H} ; \mathrm{XX}^{\prime}\right), 4.02\left(\mathrm{t}, J=6.6 \mathrm{~Hz}, 4 \mathrm{H} ; \mathrm{OCH}_{2}\right), 1.86\left(\mathrm{~m}, 4 \mathrm{H} ; \mathrm{OCH}_{2} \mathrm{CH}_{2}\right)$, 1.53 (m, $\left.4 \mathrm{H} ; \mathrm{O}\left(\mathrm{CH}_{2}\right)_{2} \mathrm{CH}_{2}\right), 1.48-1.25$ (brs, $16 \mathrm{H}$; alkyl), 1.16 (s, $18 \mathrm{H}$; tert-butyl), 0.93 ppm (m, $\left.6 \mathrm{H} ; \mathrm{CH}_{3}\right)$. MALDI-MS: $\mathrm{m} / \mathrm{z}$ calcd: 1285.7 $[M+\mathrm{H}]$, found: $1285.5 ; \mathrm{UV} / \mathrm{Vis} / \mathrm{NIR}\left(\mathrm{CHCl}_{3}\right): v_{00}^{A}=12210 \mathrm{~cm}^{-1}\left(\lambda_{00}^{A}=\right.$ $821 \mathrm{~nm}), \quad \varepsilon_{00}=256000 \mathrm{M}^{-1} \mathrm{~cm}^{-1}, \quad f=0.76 ; \quad v \lambda_{00}^{F}=12030 \mathrm{~cm}^{-1} \quad\left(\lambda_{00}^{F}=\right.$ $831 \mathrm{~nm}), \Phi_{F}=0.53$. Elemental analysis calcd $(\%)$ for $\mathrm{C}_{88} \mathrm{H}_{90} \mathrm{~B}_{2} \mathrm{~N}_{6} \mathrm{O}_{2}$ $\left[M=1285.32 \mathrm{~g} \mathrm{~mol}^{-1}\right]$ : C 82.23, H 7.06, N 6.54; found: C 81.59, H 7.11, N 6.49 .

Received: November 23, 2006

Revised: January 11, 2007

Published online: April 5, 2007

Keywords: chromophores - dyes/pigments - fluorophores · polymer welding · UV/Vis/NIR spectroscopy

[1] G. Scheibe, E. Daltrozzo, O. Wörz, J. Heiß, Z. Phys. Chem. N. F. 1969, 64, 97-114.

[2] a) E. Daltrozzo, W. Sulger, 9th International Colour Symposium, Engelberg 1985, Abstracts p. 26; b) E. Daltrozzo, PhD thesis, Technical University of Munich, 1965; c) W. Sulger, PhD thesis, University of Konstanz, 1981. 
[3] J. Fabian, H. Nakazumi, M. Matsuoka, Chem. Rev. 1992, 92, $1197-1226$.

[4] "Methine Dyes for Optical Recording Materials": E. Daltrozzo, W. Sulger, EP 0217245B1, Int.Cl. C09B 23/10, 611 B7/24,Pat.blatt, 1992, 87/15, 1-88.

[5] "New Fluorescence Dyes and their Use as Fluorescence Markers": E. Daltrozzo, A. Reiß, US Pat 6,552,199B1, 2003, 140; EP 1054039A1.

[6] W. Siebrand, J. Chem. Phys. 1967, 46, 440-447.

[7] C. Vielsack, PhD thesis, University of Konstanz, 1999, HartungGorre Verlag, Konstanz, ISSN 0930-8105, ISBN 3-89649-400-7.

[8] a) T. Schlatterer, E. Daltrozzo, J. Bühler, F. Menges, M. Winkler, 37th IUPAC Congress/27th GDCh General Meeting, Poster ORG 2-060, Berlin 1999, p. 979; b) T. Schlatterer, PhD thesis, University of Konstanz, 2001, Hartung-Gorre Verlag, Konstanz, ISBN 3-89649-658-1.

[9] A. Iqbal, M. Jost, R. Kirchmayr, J. Pfenninger, A. Rochat, O. Wallquist, Bull. Soc. Chim. Belg. 1988, 97, 615-643.

[10] F. Closs, R. Gompper, Angew. Chem. 1987, 99, 564-567; Angew. Chem. Int. Ed. Engl. 1987, 26, 552-554.
[11] The starting materials $\mathbf{1 a - 1}$ d were obtained in $30-40 \%$ yields by heating the para-substituted benzonitriles with diethyl succinate in sodium 2-methylbutan-1-olate/2-methylbutan-2-ol at reflux as described in the Ref. [9]. By this method, $\mathbf{1 e}$ could be obtained in only $7 \%$ yield.

[12] We are much obliged to Dr. H. J. Metz, Dr. K. Rode, Dr. J. Weber, and Dr.H. Wiezer, Clariant AG, for samples of 3,4dimethoxyphenyl-, 3,5-dichlorophenyl-, 4-fluorophenyl-, 3,4,5trimethoxyphenyl-, and 4-butoxyphenyl-DPP for test reactions.

[13] The smaller half-width over-compensates for the smaller transition moment, thus $\varepsilon_{00}\left(\mathbf{4 a}^{\prime}\right)$ is even higher than $\varepsilon_{00}(\mathbf{4 a})$.

[14] F. Würthner, S. Ahmed, C. Thalacker, T. Debaerdemaeker, Chem. Eur. J. 2002, 8, $4742-4750$.

[15] a) N. G. Pschirer, C. Kohl, F. Nolde, J. Qu, K. Müllen, Angew. Chem. 2006, 118, 1429-1432; Angew. Chem. Int. Ed. 2006, 45, 1401-1404; b) H. Langhals, Helv. Chim. Acta 2005, 88, 13091343.

[16] a) F. G. Bachmann, U. A. Russek, SPIE 2002, 4637, 505-518; b) K. Y. Law, Chem. Rev. 1993, 93, 449-486.

[17] P. Czerney, G. Graness, E. Birckner, F. Vollmer, W. Rettig, J. Photochem. Photobiol. A 1995, 89, 31-36. 